
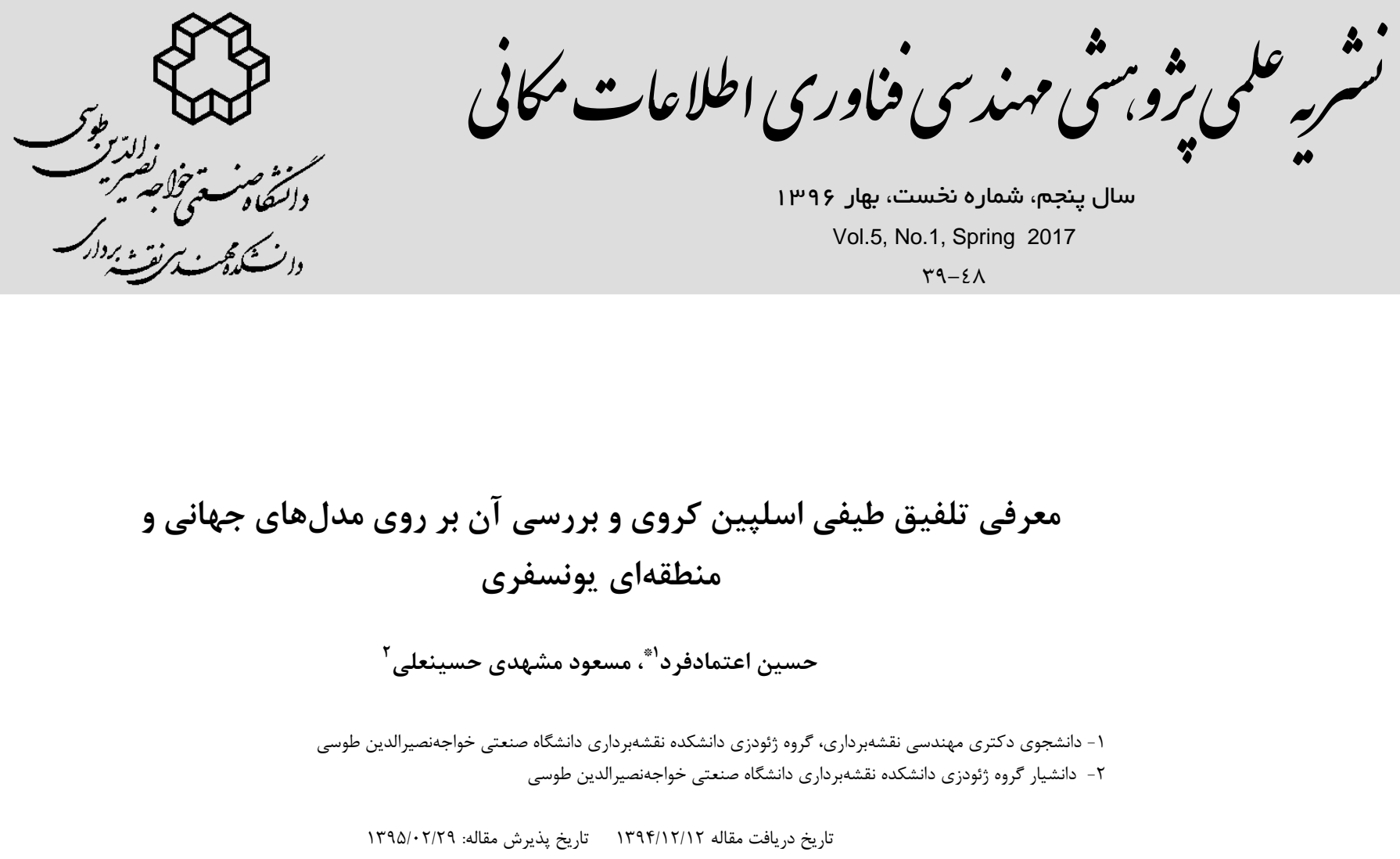

جكيده

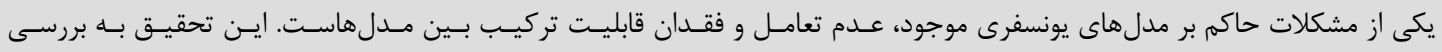

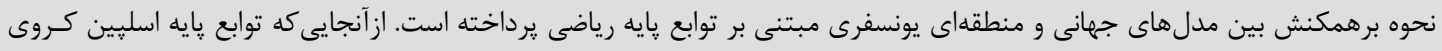

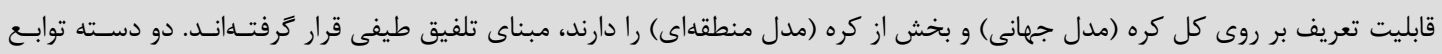

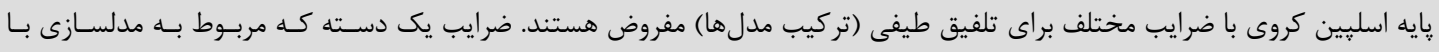

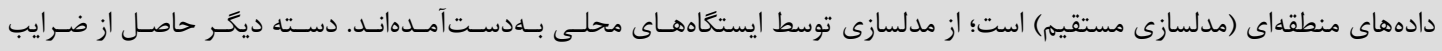

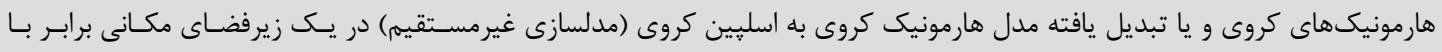

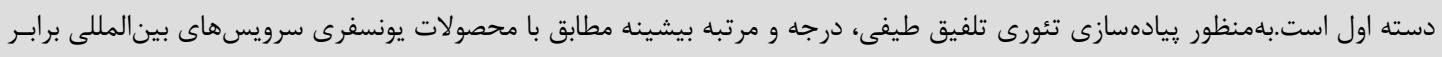

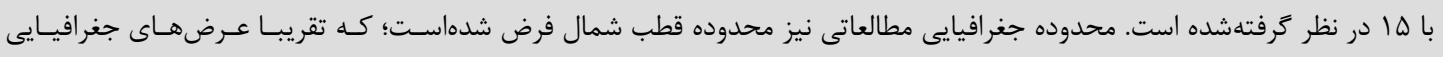

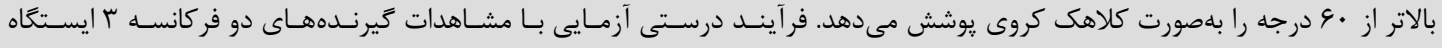

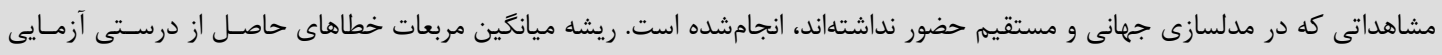

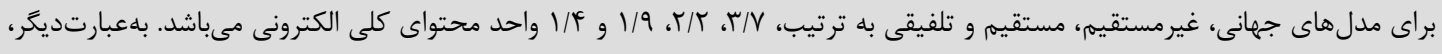

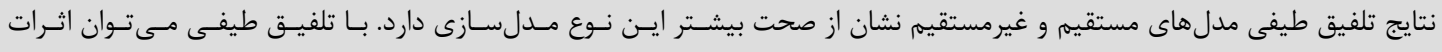

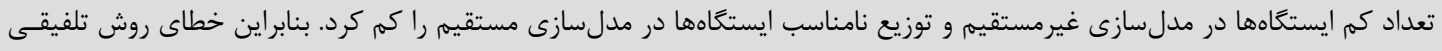
بلاصورت كلى كمتر از دو روش ديگر است.

وازههاى كليدى: تلفيق طيفى، اسليين كروى، يونسفر. 


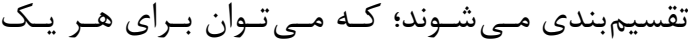

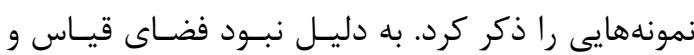
مبناى يكسان، بدون شك تركيب مدل هـاى يونسـفرى

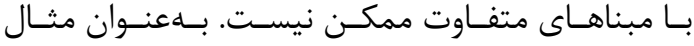
نمى توان مدلى تجربى را با مدلى فيزيكى تركيسب كـرد.

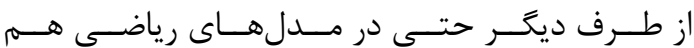

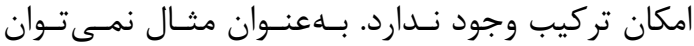

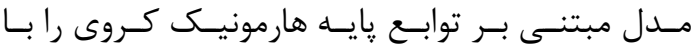

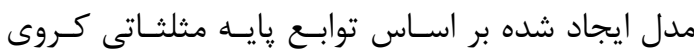

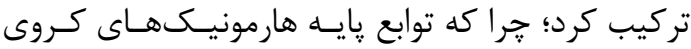
جواب حاصل از حل معادلـه لإِـلاس روى كـره اســـ

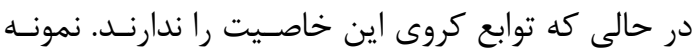
مذكور يكى از بهترين نمونههايى اسـت كـهـ توابـع بايسهـ

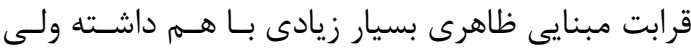
بازهم قابليت تركيب ندارند. اين تحقيق به دنبـال بررسـى امكـان تركيـب دو مــدل رياضى جهـانى و مــدل رياضـى منطقـهاى اسـت. تنهـا تركيب دو مدل در فضايى ممكن است كه مبناى توابـع ماضع

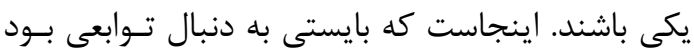

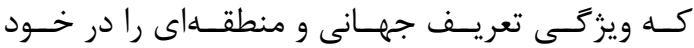
داشته باشند. تئورى تمركز مكان طيفى بهصورت بهينه

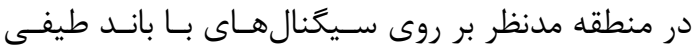
محدود تعريفشده است. اين تئسورى مسىتوانـد فضـاى

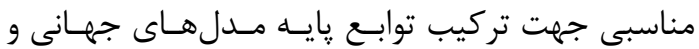

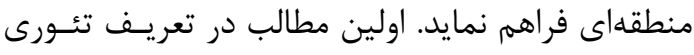

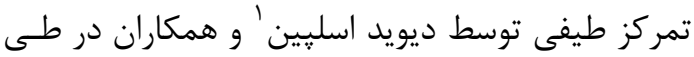

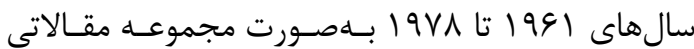

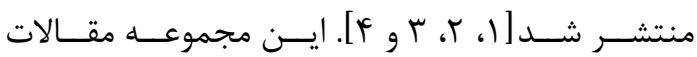
به بررسى مساله تمركز طيفى در يك بعد يرداختـهانـد. در مطالعات اخيــر در ايـن زمينـهـ سـيمونز و همكـاران

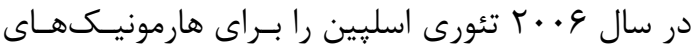

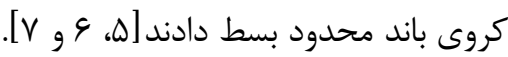

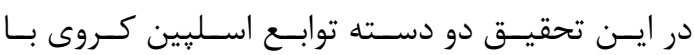

\footnotetext{
${ }^{1}$ Slepian
}

- 1 - - 1قدمه

معمولا مدلهاى متعددى براى رفتار يك يديده طبيعى

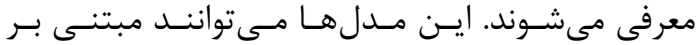

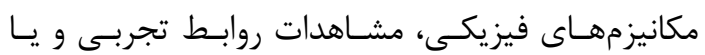
مدلهاى صرفا رياضى باشند. يكى از مشكلات حاكم بـر

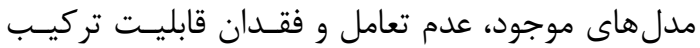

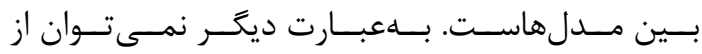

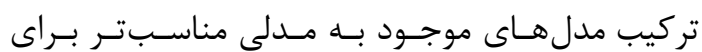
تخمين رفتار يديدهها رسيد. برخى از مدلهاى فيزيكى تنها بـا يـارهاى از مشــاهدات

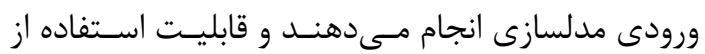
ديكر مدلها را ندارند. از طرف ديكر مسدلهـاى تجرئس با دادههاى ويزه و در بازههاى زمانى خاصى مورد اعتماد

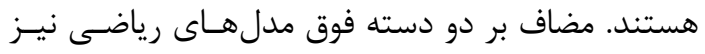

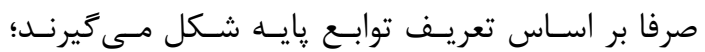

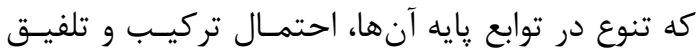

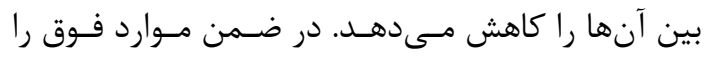

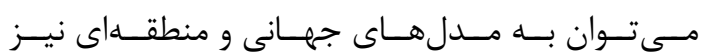
تقسيمبندى كرد. در اين صورت تعامل و تركيب مدلها

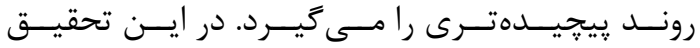

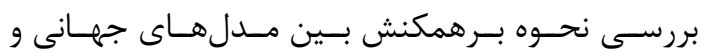

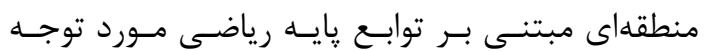

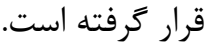
بهمنظور بررسى دقيقتر، در اين تحقيق به رفتار يونسفر

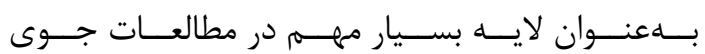
يرداختهشده است. يونسفر بهعنوان لايهاى از اتمسفر بـا لـا

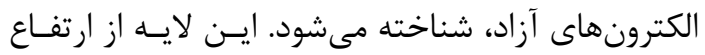

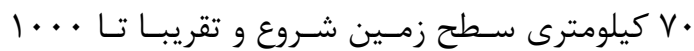

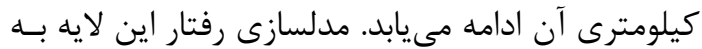
دليل تاثير زياد بر روى مشاهدات سيستمهــاى تعيسين

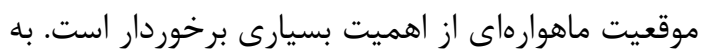
همين دليل مدلهاى يونسفرى زيادى توليد، ييشبينى برئ و عرضه مىشوند.

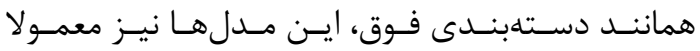

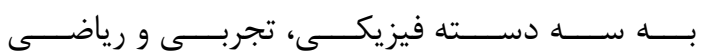


اســلِين كــروى و مشـــاهدات دو فر كانســـه ســامانه

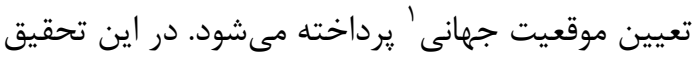
اين روش را مدلسازى مستقيم نامخذارى كردهايـهم. زيـر بخش r-r نيز به روش تلفيق طيفى بين ايسن دو مـدل اختصاص دادهده است.

ז-1 - مدل اسليين از توابع هارمونيك كروى: در اينجا توابع هارمونيك كروى و ضرايب آن بـهـعنـوان كام نخست كار قرار مى گيرند. توابـع هارمونيـى كـروى

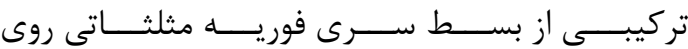

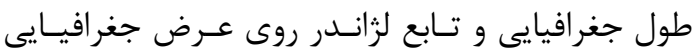

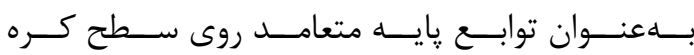
شناختهشده هستند. بيان رياضى مولفـه قـائم محتـواى باى

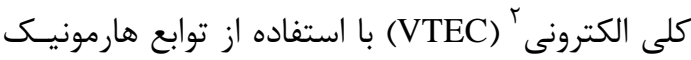

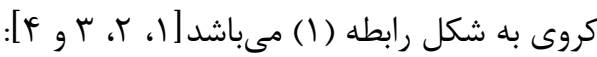

(1) (1)

$$
\operatorname{VTEC}\left(\theta_{I P P}, \lambda_{I P P}\right)=\sum_{l=0}^{K} \sum_{m=-l}^{l} \psi_{l m} Y_{l m}\left(\theta_{I P P}, \lambda_{I P P}\right)
$$

(T) (T)

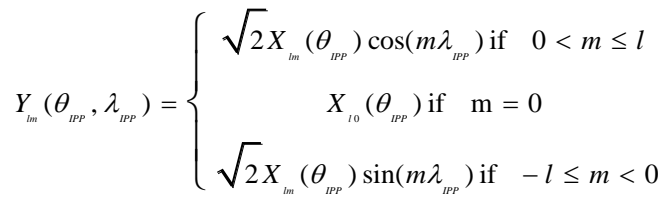

رابطه (广)

$$
\begin{aligned}
& X_{l m}\left(\theta_{p p}\right)=(-1)^{m}\left(\frac{2 l+1}{4 \pi}\right)^{1 / 2}\left[\frac{(l-m) !}{(l+m) !}\right]^{1 / 2} P_{l m}\left(\cos \theta_{p p p}\right) \\
& P_{l m}(\mu)=\frac{1}{2^{\prime} l !}\left(1-\mu^{2}\right)^{m / 2}\left(\frac{d}{d \mu}\right)^{l+m}(1-\mu)^{\prime}
\end{aligned}
$$

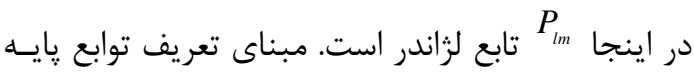

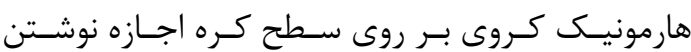
رابطه (ه) رامى دهد:

$\int_{\Omega} Y_{l m} Y_{l^{\prime} m} d \Omega=\delta_{l l} \delta_{m m}$

رابطه (a)

\footnotetext{
${ }^{1}$ Global Positioning System (GPS)

${ }^{2}$ Vertical Total Electron Content (VTEC)
}

ضرايب مختلف براى تلفيـق طيفى (تركيـب مــدلهــا)

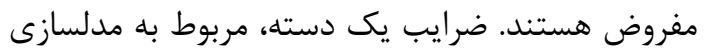

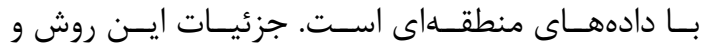

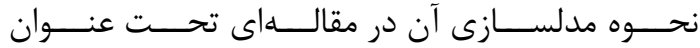
اسليين كروى بهعنوان يك روش جديد جهت مدلسازى

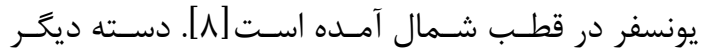
حاصل از ضرايب هارمونيكهاى كروى و يا تبديل يافته

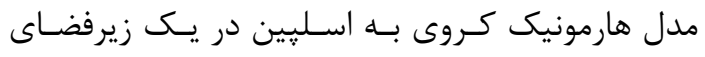

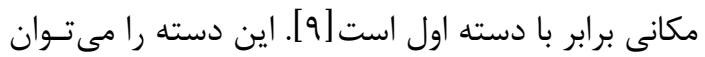

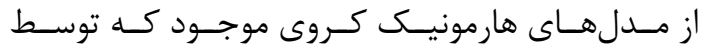

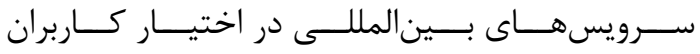

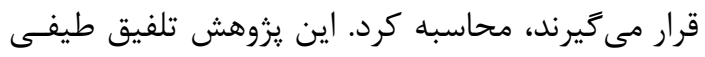

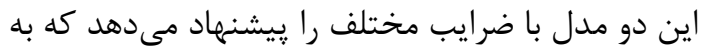
نام تلفيق طيفى اسليين كروى معرفى مىشود. تئـورى و روش انجام تلفيق طيفى اسلِين كروى براى نخستين

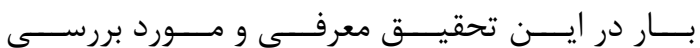

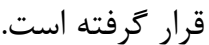
در بخـش دوم ايـن تحقيـق ابتــدا بــه معرفـى دو روش

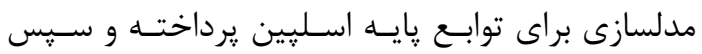

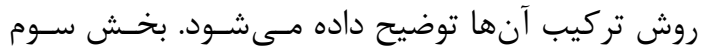
به بيادهسازى اين روش در ناحيه قطب شمال بهعنــوان

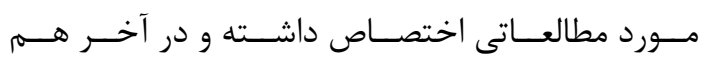
جمعبندى و نتيجه كيرى آورده شده است. r- (- تئورى مسئله

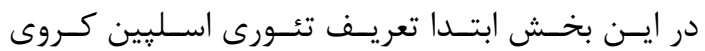

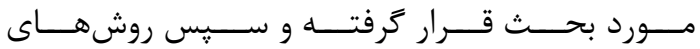
محاسـبه ضـرايب مربـوط بــه توابـع اسـلِين كـروى

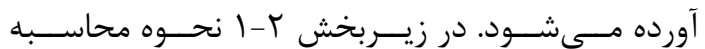

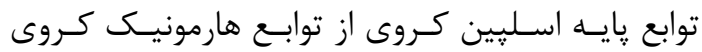

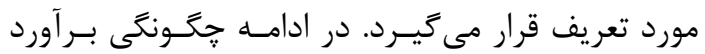

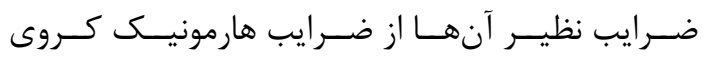

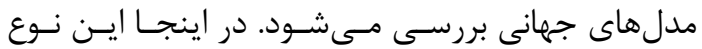

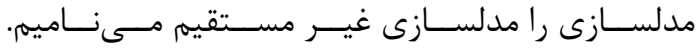

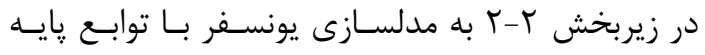


اينجا $\delta$ دلتاى كرونكر، $\Omega$ سـطح كـره و $2 \Omega$ المـان خواهيم داشت:

$$
\beta=\frac{\sum_{l=0}^{K} \sum_{m=-l}^{l} \psi_{l m} \sum_{l^{\prime}=0}^{K} \sum_{m^{\prime}=-l^{\prime}}^{l^{\prime}} D_{l m, l^{\prime} m^{\prime}} \psi_{l^{\prime} m^{\prime}}}{\sum_{l=0}^{K} \sum_{m=-l}^{l} \psi_{l m}^{2}}
$$

(V) رابطه

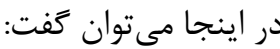

$$
D_{l m, l^{\prime} m^{\prime}}=\int_{R} Y_{l m} Y_{l^{\prime} m^{\prime}} d \Omega
$$

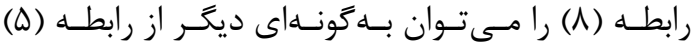

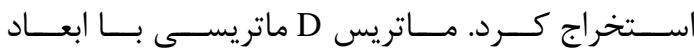
 اكر رابطه فوق بهصورت ماتريسى نوشته شود، مسى جـوان همان مسئله جبرى مقادير ويـزه را اسـتخراج كـرد [هان].

$$
\lambda \psi=\mathrm{D} \psi
$$

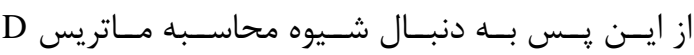

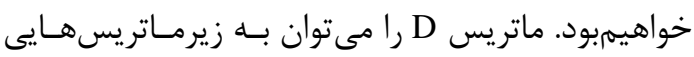
به شكل رابطه (• () تقسيم كرد [ه]].

$\mathrm{D}=\operatorname{diag}\left\{\mathrm{D}_{0}, \mathrm{D}_{1}, \mathrm{D}_{1}, \ldots, \mathrm{D}_{\mathrm{K}}, \mathrm{D}_{\mathrm{K}}\right\}$

رابطه (•) (1) در اين رابطه D نشـاندهنــــ محاسـبه يعنى محاسبه ماتريس D در حالتى كه مرتبه آن صـفر

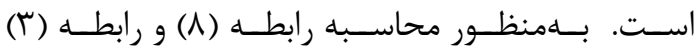
خواهيم داشت [ها

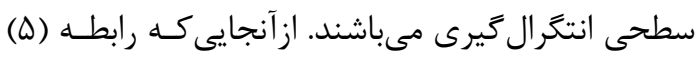
فقط و فقط بر روى تمامى سطح كـره صـدق مسى كنـد، قطعا توابع مربوط به هارمونيكهاى كروى روى بخشى فئس از كره متعامد نيستند. حال مسئله اين است كه بايستى به دنبال متعامد كردن توابع و بهينه كردن تمركز آنها در سطح منطقه مدنظر بود. بدين منظور تئورى اسليين

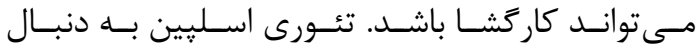

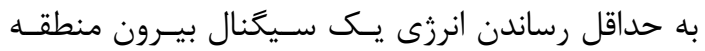

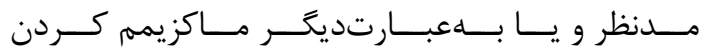

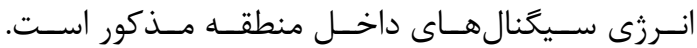
اين تئورى توسط سيمونز بر روى هارمونيكهاى كروى

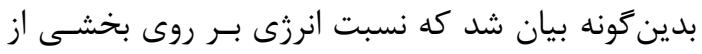
سطح كره به انرزى بر روى كل كره مـاكزيمم شـود [هـ].

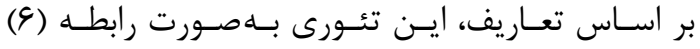

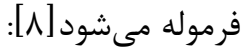
رابطه (9) $\beta=\frac{\left\|\operatorname{VTEC}\left(\theta_{I P P}, \lambda_{I P P}\right)\right\|_{R}^{2}}{\left\|\operatorname{VTEC}\left(\theta_{I P P}, \lambda_{I P P}\right)\right\|_{\Omega}^{2}}=\frac{\int_{R} \operatorname{VTEC} C^{2}\left(\theta_{I P P}, \lambda_{I P P}\right) \mathrm{d} \Omega}{\int_{\Omega} \operatorname{VTEC} C^{2}\left(\theta_{I P P}, \lambda_{I P P}\right) \mathrm{d} \Omega}=\max$.

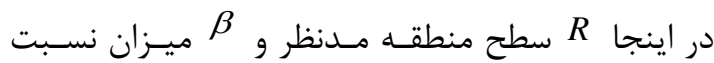

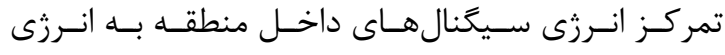

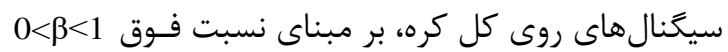
مىباشند. كه البته با جايخذارى رابطه (1) در رابطه فـوق

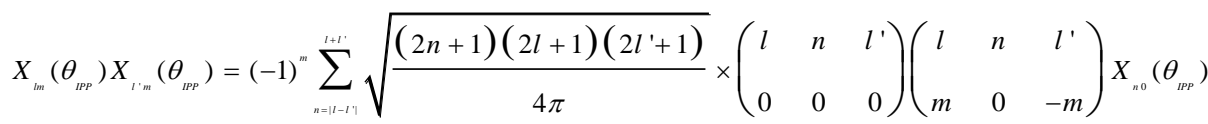

رابطه (1)

حال مىتوان با استفاده از بردارهاى ويزه بهدستآمـده،

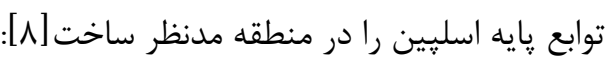
$\mathrm{S}_{\mathrm{jm}}=\mathrm{V}_{\mathrm{jm}}^{\mathrm{T}} \mathrm{Y}_{\text {;m }}$

رابطه (1) (I)

همجنين به روش مشابه مى توان ضرايب اين توابع پايسـه

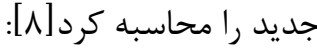
$\Psi_{\mathrm{jm}}=\mathrm{V}_{\mathrm{jm}}^{-1} \Psi_{; \mathrm{m}}$ رابطه (I)

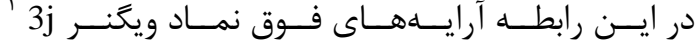

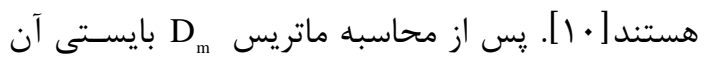
را به مقدارها و بردارهاى ويزه تبديل كرد:

$$
\mathrm{D}_{\mathrm{m}}=\mathrm{V}_{\mathrm{m}} \Lambda_{\mathrm{m}} \mathrm{V}_{\mathrm{m}}^{-1} \quad \text { (I) رابطه }
$$

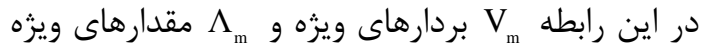

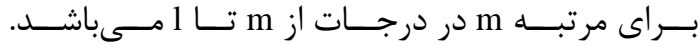

${ }^{1}$ 3j-Wigner 
نيمساعته) از اين اختلاف ميانكَين گيرى كرده و در آخر مقدار حاصل را به مقادير رابطه (9) اضـافه مسى كنسيم. در ادامه روابط محاسبات فوق آمده است [ ب ال]. $\triangle S T E C_{i}=S T E C_{P, i}-S T E C_{L, i}$

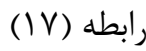

$$
\triangle \operatorname{STEC}_{M}=\frac{\sum_{i=1}^{M} \Delta S T E C_{i}}{M}
$$

$S T E C_{\text {smooth }}=S T E C_{L}+\triangle S T E C_{M}$

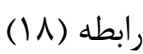

رابطه (19)

بس از آمـاده شــن مقــادير مشـاهدات بايسـتى آنهـا

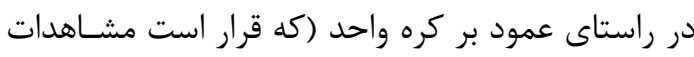

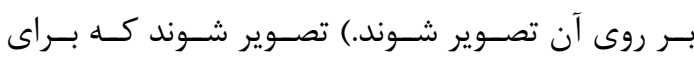
اين منظور از رابطه زير استفاده مىشود: $V T E C=\cos (z) \times S T E C_{\text {smoot }}$

رابطه (ץ)

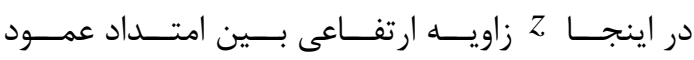

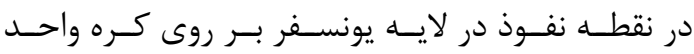

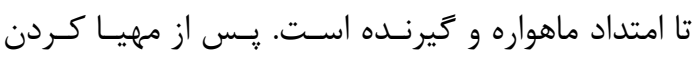

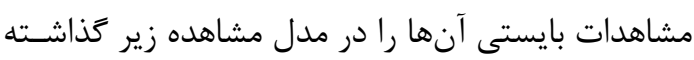
و به روش كمترين مربعات حل كنيه: $\mathrm{L}=\mathrm{AX}$

رابطه (YI)

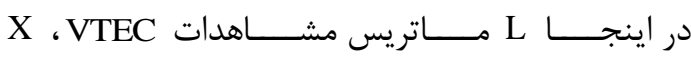

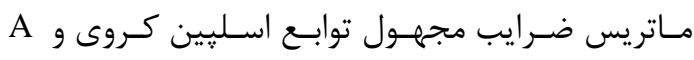
ماتريس ساختار مىباشند. لازم به ذكر است كه بايستى

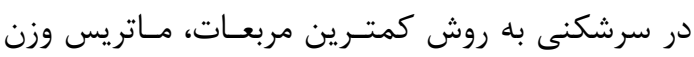

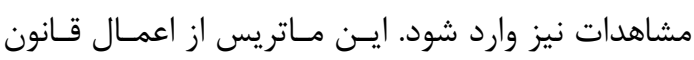
انتشار خطاها بر روى روابط ها تا • ب بهدست مى آيد.

\section{r-r- تلفيق طيفى اسليين كروى}

در اين قسمت بايستى دو مدل غير مستقيم و مسـتقيم

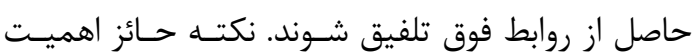

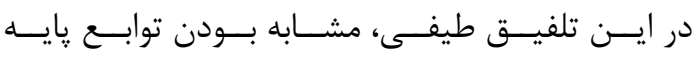
اين دو دسته است. بهمنظور تلفيق طيفى اين دو دسته

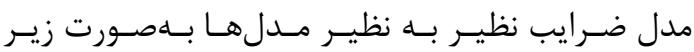

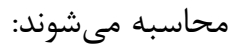

\section{r-r- مدل اسلِين از مشاهدات مستقيم}

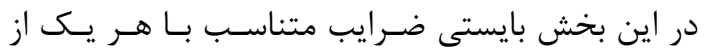

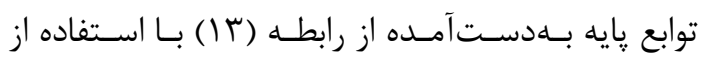

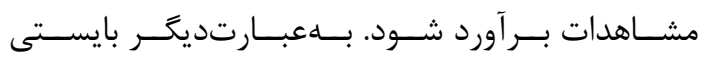

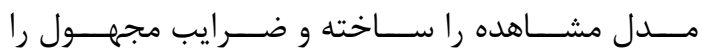

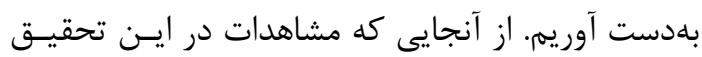

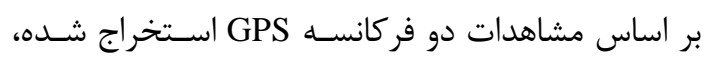
در كام نخست بايستى مشـاهدات را از فايـلـهـاى خـام

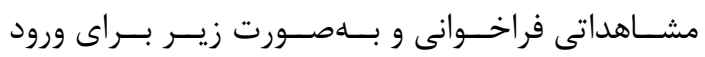
در معادلات مشاهدات آماده شوند [ [1 1]:

$$
\operatorname{STEC}_{P}=\frac{f_{1}^{2}\left(P_{1}-P_{2}-B_{i}-B^{p}\right)}{40.3\left(\frac{f_{1}^{2}}{f_{2}^{2}}-1\right)}
$$

رابطه (Q) رابطه (1) $S T E C_{L}=\frac{f_{1}^{2}\left(\lambda_{1} L_{1}-\lambda_{2} L_{2}-\lambda_{1} N_{1}+\lambda_{2} N_{2}-b_{i}-b^{p}\right)}{40.3\left(\frac{f_{1}^{2}}{f_{2}^{2}}-1\right)}$

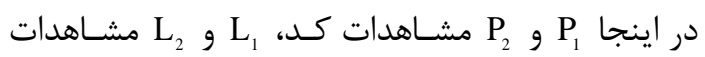

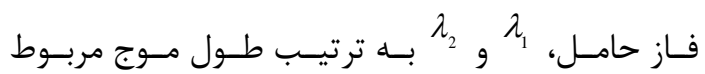

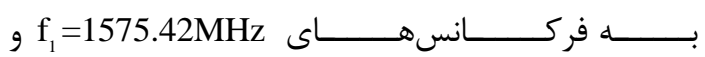

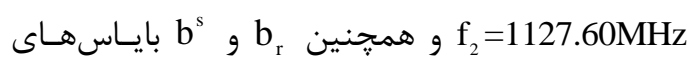

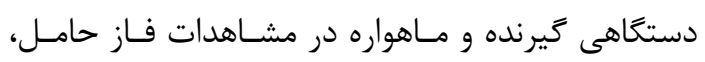

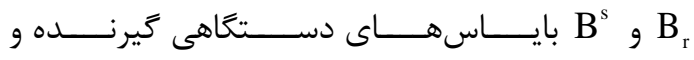
ماهواره در مشاهدات كد و در آخر STEC و مكت محتواى الكترونى كل مسير سـير سـيخنال مسىباشـــند.

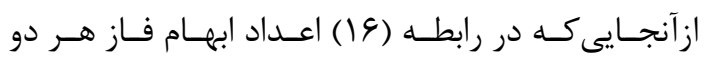

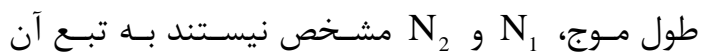
مقدار حاصل از رابطه (ع) باياس داشته و قابل اعتمـاد

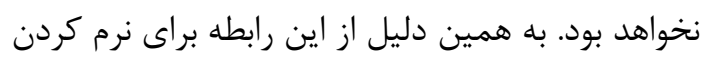

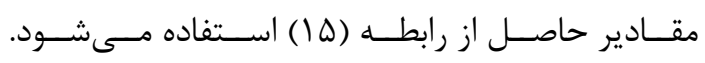
بهمنظور نرمسازى ابتدا بايستى اختلاف بـين دو مقـدار

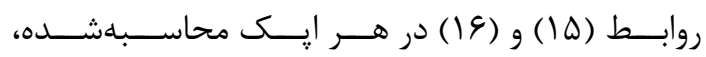

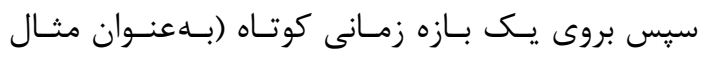


ا ساعته براى روز اول دسـامبر ها • r، از وب سـرويس CODE

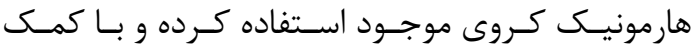

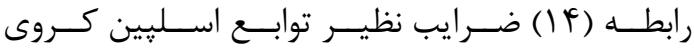

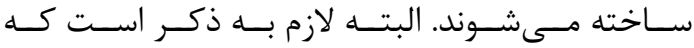

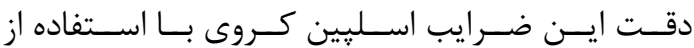

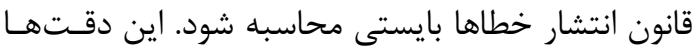
در قسمت تركيب طيفى به كار مىرود. از آنجايى كه اين تحقيق به دنبال بررسى تلفيق طيفى دئ مئى

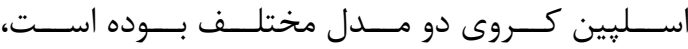
مشاهدات ايستخاههاى شبكههاى منطقهاى شمال ارويـا

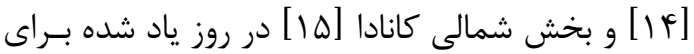
مدلسازى مستقيم مــورد اسـتفاده قـرار كرفتــه اسـت. در شـكل (1) موقعيـت جغرافيـايى ايــن ايسـتخاههــا نشان دادهشه است.

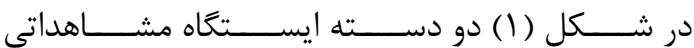
معرفى شدهانـد. دسـته اول كـهـ بـه نـام نقـاط كنتـــل

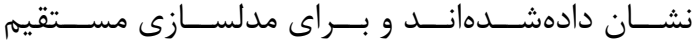

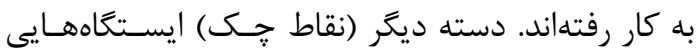

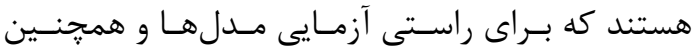
تلفيق طيفى ييشنهادى، به كار مىرود. مورد بسيار مهرم

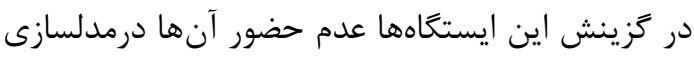

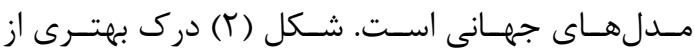

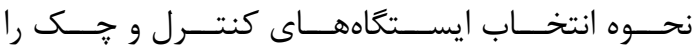
بلهست مىدهد. در اين شكل نقاط نفوذ در لايه يونسفر

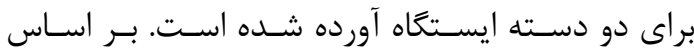
اين شكل مسى تـوان ديـــ كـه مشــاهدات يـك ايسـتخاه در قسمت شمال ارويـا و دو ايسـتخاه در شـمال كانـادا

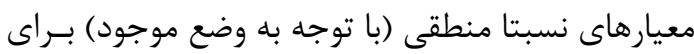

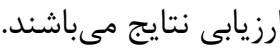

\footnotetext{
${ }^{2}$ Center of Orbit Determination in Europe (CODE)
}

رابطه (Tr)

$\overline{\operatorname{VTEC}}(\theta, \lambda)=\left(\sum_{j=1}^{n} \alpha_{j} \Psi_{j}^{1}+\beta_{j} \Psi_{j}^{2}\right) S_{j}(\theta, \lambda)$

در اينجا $\Psi_{j}^{1}$ ض ضرايب اسليين كروى مدل مستقيم مىباشـند. تعداد توابع يايه اسليين كروى استفادهــده و

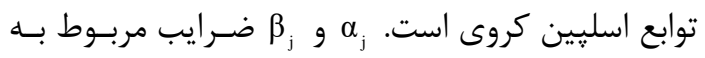

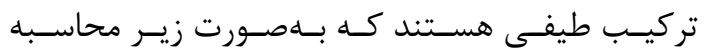

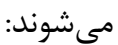
رابطه (Tr)

$$
\alpha_{j}=\frac{\sigma_{j, 1}^{2}}{\sigma_{j, 1}^{2}+\sigma_{j, 2}^{2}} \quad, \quad \beta_{j}=\frac{\sigma_{j, 2}^{2}}{\sigma_{j, 1}^{2}+\sigma_{j, 2}^{2}}
$$

در اينجا

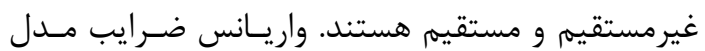

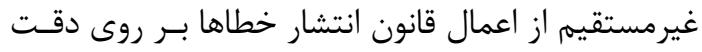

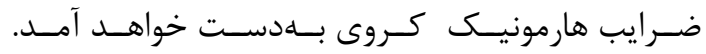
واريانس ضرايب مدل مستقيم نيـز از مـاتريس وريــانس هـ كووريــانس سرشــكنى كمتـــرين مربعـــات مربوطــــه، قابل حصول است.

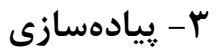

بهمنظور ييادهسازى روشهاى ذكر شده در اين تحقيـق بايسـتى ابتــدا منطقــهـ مطالعـاتى و بيشــينه درجــهـه و مرتبه هارمونيـكهـاى كـروى مـدنظر را تعيـين كـرد. بيشينه درجه و مرتبه مطـابق بـا محصـولات يونسـفرى

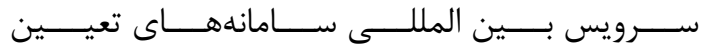
موقعيت ماهوارهاى ' برابر با ها در نظر زرفتهشدهاست. محدوده جغرافيايى مطالعاتى نيز محدوده قطـب شـمال فرض شدهاست؛ كه تقريبا عرضهاى جغرافيايى بالاتر از

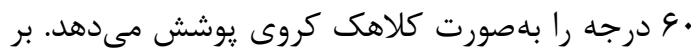
اسـاس ايسـن منطقـهـ و تعـداد هارمونيـكـهــاى كـروى توابع پايه اسليِين كروى با رابطه (T) ساخته مىشوند.

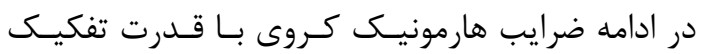

${ }^{1}$ International GNSS Service (IGS) 
رابطه (•r) محاسبهشده و آنها براى ورود بـه دسـتخاه

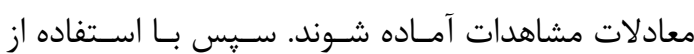
تكنيك كمترين مربعات ضرايب توابـع اسـليين كـروى

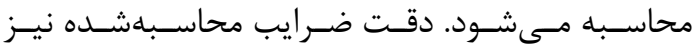

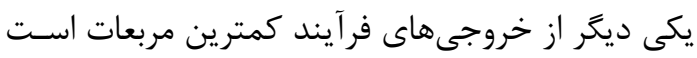
كه در بخش تركيب طيفى به كار كرفته مي شوند.

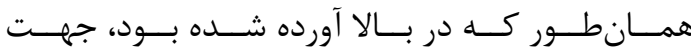
درستى آزمايى مدلسازى از مشاهدات ايستخاههاى نقاط

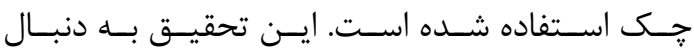
بررسى جگگونكى تلفيق طيفـى بـوده اسـت؛ بــه همـين

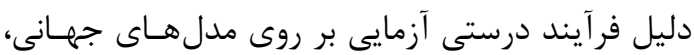

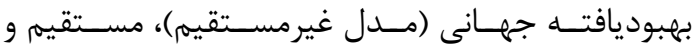
همجنين تلفيقى انجامشده است.

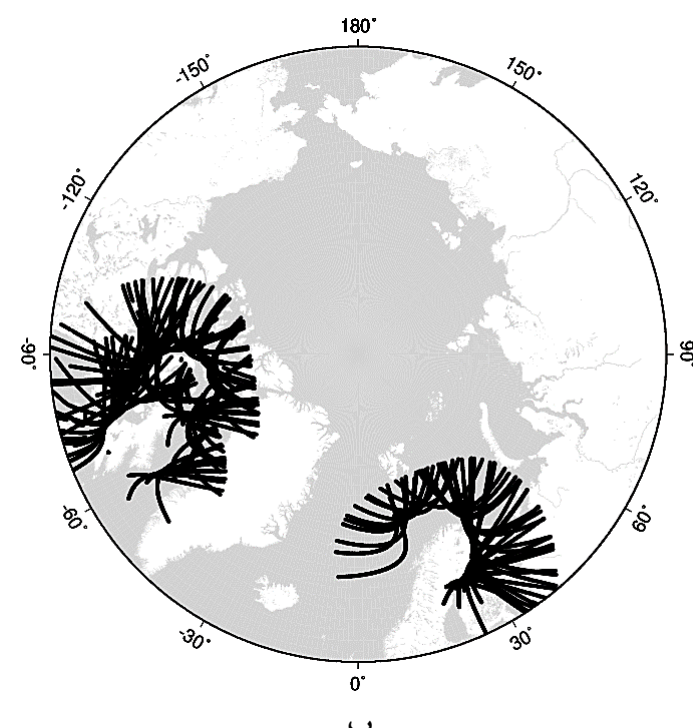

شكل r : موقعيت مكانى نقاط نفوذ يونسفرى (الف: ايستخاههاى كنترل و (ب: ايستخاههاى جـى شكل زير مقادير اين كميت را نشان مي إندهد

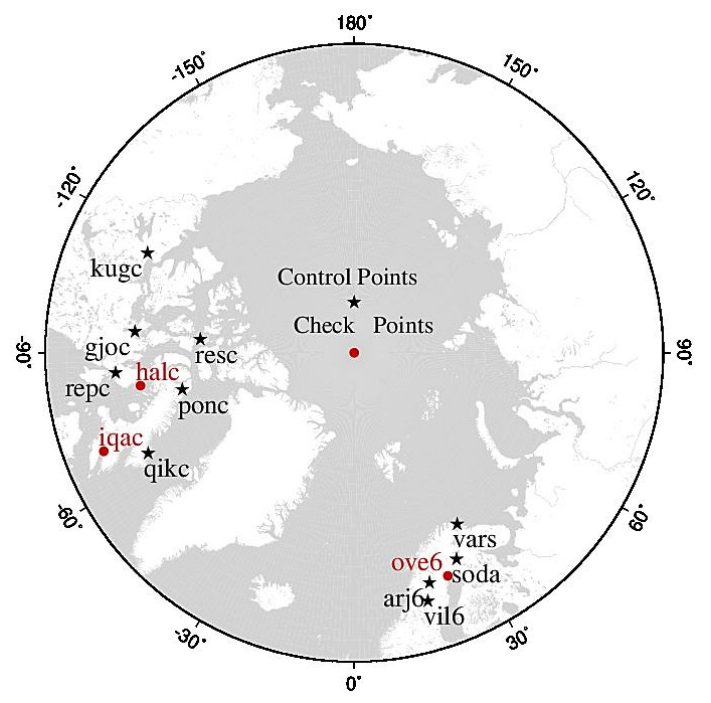

شكل ا : موقعيت جغر افيايى نقاط مورداستفاده در مدلسازى مستقيم

1.

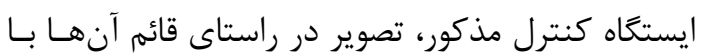

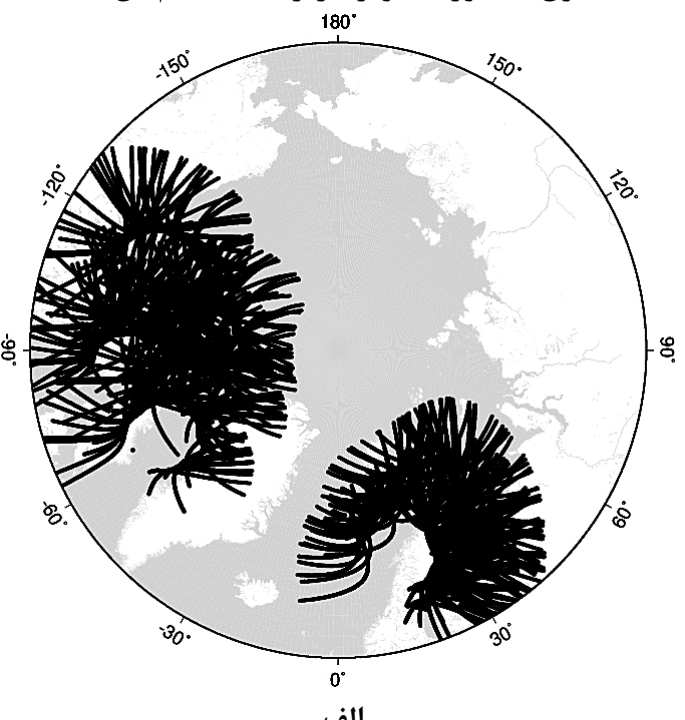

الف

بدين منظور مختصات نقاط نفوذ يونسـفرى مشـاهدات

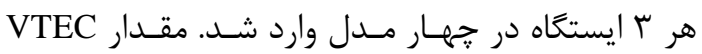
محاسبهشده از آنها با مقدار مشاهداتى نظير آن نقـاط نفوذ مقايسه شده و بهصـورت ريشـهـ ميـانگَين مربعـات

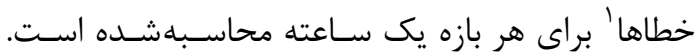

${ }^{1}$ Root Mean Square Error 


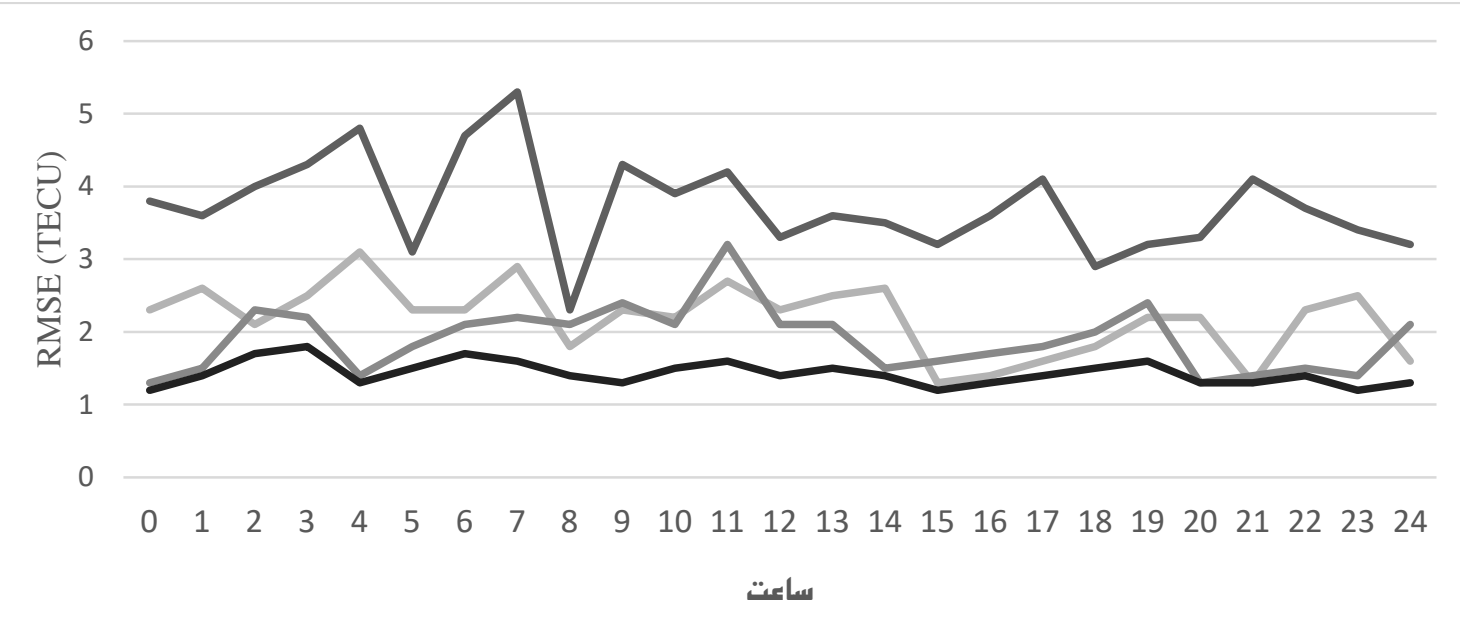

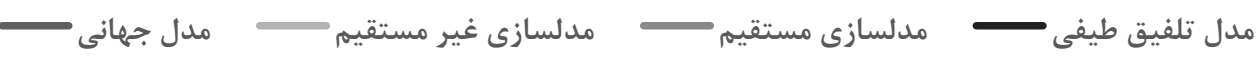

شكل ץ : مقادير RMSE براى مدلهاى جهانى، غيرمستقيم، مستقيم و تلفيقى در روز اول دسامبر سال ها+ץ

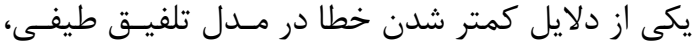

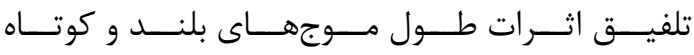
يونوسفرى موجود در مدلهاى غيرمسـتقيم و مســقيم

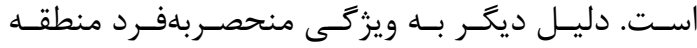

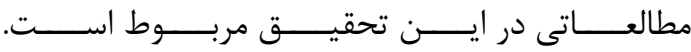

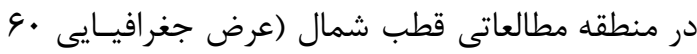
تا • 9)، در بخشى از ايـن كلاهـك كـهـ رو بـهـ خورشـيد

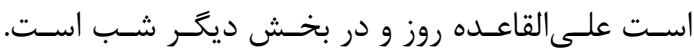

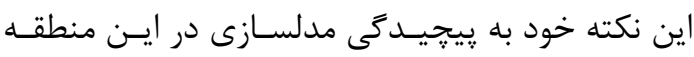

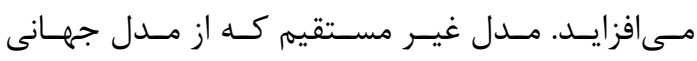

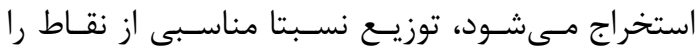

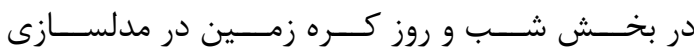
به كار مى گیرد. ولى نقطهضعف مدل هاى جهاى جهانى تعـداد بسيار كم ايستخاه GNSS در قطب شمال است. بنابراين

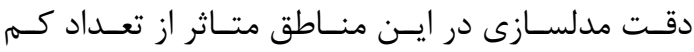

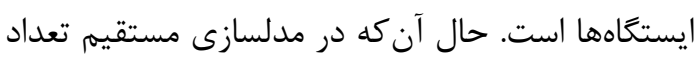

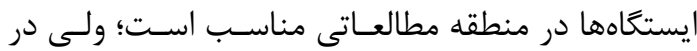

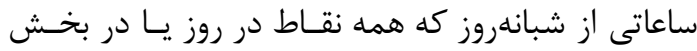
شب قرار مى گيرند، مدل دقت و كيفيـت سـاعات ديخــر

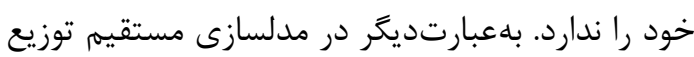
نامناسب ايستخاهها دقت مدلسازى را متاثر مى كنـد. بـا توجه به اين نكات، با تلفيق طيفى مى توان اثرات تعـداد

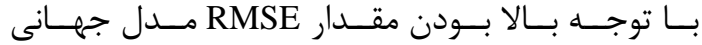
در شكل فوق، مىتوان دريافت كه مدل جهانى عملكـرد

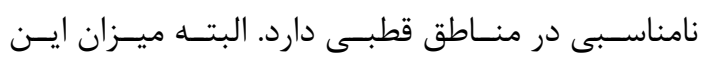

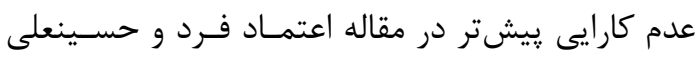

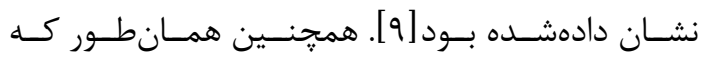
در شكل (Y) ديده مىشود در برخسى سـاعات عملكـرد

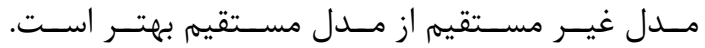
بهعبارتديگر بر اساس نتايج حاصل از نقاط جـى، مـدل مـل

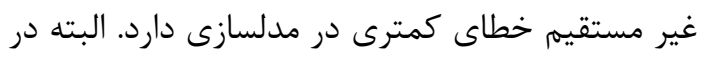
ساير موارد مدل سازى مستقيم درسـتى بيشـترى دارد. بهمنظور بررسى كلى ميانگين RMSE در طول اين بازه

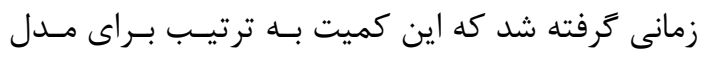

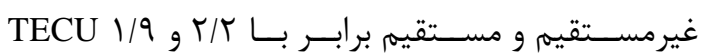
مىباشد. علاوه بر موارد فـوق در شـكل (ب) ديـــهـ مسىشـود كـهـ

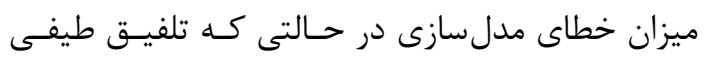
انجام مىشود تقريبا از دو مدل فوقالـذكر كمتــر اسـت. نكته ديخر كه در شكل ديـده مسىشـود خطـاى نسـبتا يكسان مدلسازى در كـل بــازه زمـانى مطالعـاتى اسـت.

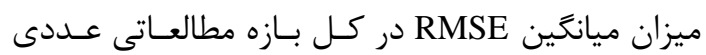

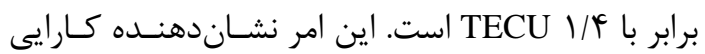
تلفيق طيفى در مورد مطالعاتى اين تحقيق است. 
و TECU T/T بهدست آمــدهانـد. در آخـر نتـايج تلفيـق

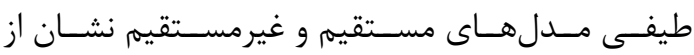
صحت بيشتر مدلسازى داشت. بهطورى RMSE حاصل

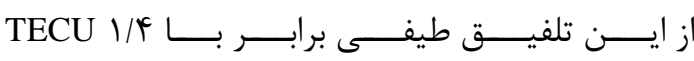
محاسبهشده است.

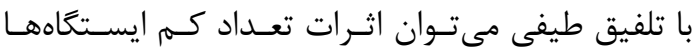
در مدلسازى غير مستقيم و توزيع نامناسب ايسـتخاههــا در مدلسازى مستقيم را كم كرد. بنابراين خطساى روش تلفيقى بلصورت كلى كمتر از دو روش ديخر است. همانطور كه در بالا آورده شده بود، ايسن تحقيـق تنهـا

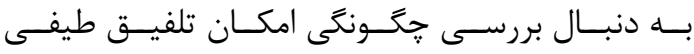

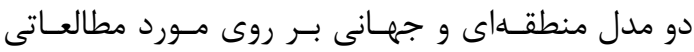
خاصى بوده است. بهمنظور بررسى عميقتر در تحقيقات آتى ييشنهاد مىشود كه از توزيع ايستكاههاى بيشـترى

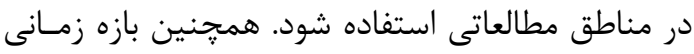
بلندترى مورد مطالعه قرار بخيرد؛ جرا كه امكان حضور بـاني تمامى يديدهاى يونسفرى در آن ديده شود.

[1] D. Slepian, and H. O. Pollak, "Prolate Spheroidal Wave functions Fourier Analysis and Uncertainty I.”, Bell Sys. Tech. J. 40, 1, 43-63, 1961.

[2] D. Slepian, and E. Sonnenblick, "Eigenvalues associated with prolate spheroidal wave functions of zero order", Bell Syst. Tech. J., 44, pp. 1745-1759, 1965.

[3] D. Slepian, "On Bandwidth.", Proceedings of the IEEE 64, 3, 1976.

[4] D. Slepian, "Prolate Spheroidal Wave Functions, Fourier Analysis and Uncertainty V: The Discrete Case", Bell Syst. Tech. J. 57, 2, 1371-1430, 1978.

[5] F. J. Simons, F. A. Dahlen, and M. A. Wieczorek, "Spatiospectral Concentration on a Sphere", SIAM Review 48, 3 (January), 504-536, 2006.

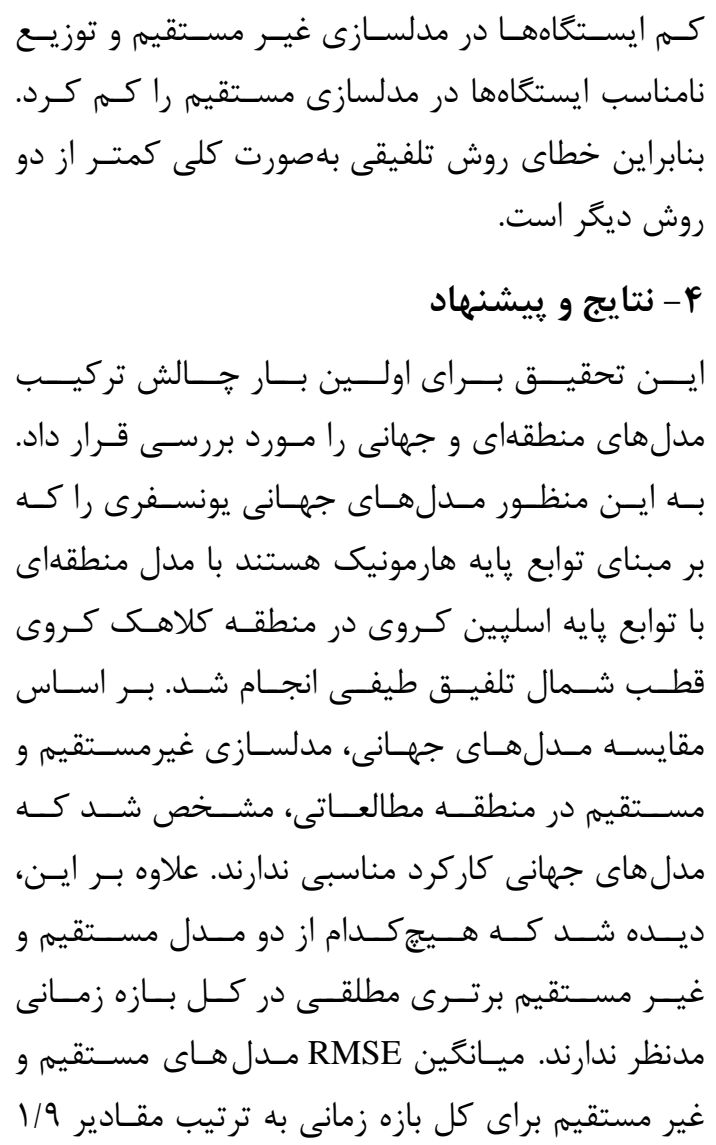

\section{مراجع}

[6] F. J. Simons, J. C. Hawthorne, and C. D. Beggan, "Efficient analysis and representation of geophysical processes using localized spherical basis functions", In Wavelets XIII, V. K. Goyal, M. Papadakis, and D. Van De Ville, Eds. Vol. 7446. SPIE, San Diego, CA, USA, 74460G15, 2009.

[7] F. J. Simons, "Slepian functions and their use in signal estimation and spectral analysis", Handbook of Geomathematics, Eds. Thomas Sonar, Zuhair M. Nashed, and Willi Freeden. Heidelberg, Germany: Springer, 891-923, 2010.

[8] H. Etemadfard, M. M. Hossainali, "Spherical Slepian as a New Method for Ionospheric Modeling in Arctic Region", Journal of Atmospheric and Solar-Terrestrial Physics, under review, 2016.

[9] H. Etemadfard, M. M. Hossainali, 
"Application of Slepian Theory for Improving the Accuracy of Global Ionosphere Models in the Arctic Region", J. Geophys. Res. Space Physics, 120, 2015.

[10] D. L. Donoho, P. B. Stark, "Uncertainty principles and signal recovery", SIAM J. Appl. Math., 49, pp. 906-931, 1989.

[11] X. Liao, "Carrier Phase Based Ionosphere Recovery over a Regional Area GPS Network", UCGE Reports, Number 20143, The University of Calgary, Calgary, Alberta, Canada, 2000.

[12] X. Liao, Y. Gao, "High-Precision ionosphere TEC Recovery Using a Regional Area GPS Network", Navigation, Vol. 48, No. 2, 101-111, 2001.

[13] Website:

ftp://ftp.unibe.ch/aiub/CODE/2015/

[14] Website:

http://www.epncb.oma.be/_networkdata/stati onlist.php

[15] Website:

http://chain.physics.unb.ca/chain/pages/stati ons/ 


\title{
Introduction of Spherical Slepian Spectral Combination and Its Investigation on Global and Regional Ionospheric Models
}

\author{
Hosein Etemadfard ${ }^{* 1}$, Masoud Mashhadi Hossainali ${ }^{2}$ \\ 1- PhD. Student, Faculty of Geodesy and Geomatics Engineering, K. N. Toosi University of Technology. \\ 2- Associate Professor in Geodesy, Faculty of Geodesy and Geomatics Engineering, K. N. Toosi University of Technology.
}

\begin{abstract}
Lack of interaction and ability to combine between ionosphere models are important problems among them. This study has investigated the interaction between global and regional ionospheric models which are according to the base mathematical functions. Here, spherical Slepian base functions have been suggested for spectral combination. They can be defined in global and regional scales. Two sets of coefficient were assumed for spherical Slepian base function. One set (direct model) is extracted from the direct observation of GPS stations. Another set (indirect model) is derived from spherical harmonic products of Global Ionosphere Models (GIMs). GIM's efficiency has been modified on a sub-space which was equal to pervious set.

Maximum degree has considered equal to 15 for implementation of spherical Slepian spectral combination theory. Also, the Arctic region has been taken as study area where it is the spherical cap by latitude upper than 60 degrees. Observations of three GPS stations are used for evaluation of models. They have not contributed for direct and indirect modelling. Root Mean Square of Errors (RMSEs) for GIMs, direct, indirect and combining models are equal to $3.7,2.2,1.9,1.4 \mathrm{TECU}$, respectively. In other words, results show that combining method has improved the ionospheric modelling here. The combining method can decrease the effects of the lack of stations in the indirect model and the inappropriate distribution of stations in the direct one. Therefore, the RMSE of the combining model is less than other models in the Arctic region.
\end{abstract}

Key words: Spectral Combination, Spherical Slepian, Ionosphere

Correspondence Address No. 1346, ValiAsr Street, Mirdamad cross, Geomatics Engineering Faculty, K.N. Toosi University of Technology, Tehran, Iran Tel +98 2188786212 .

Email: hossein_etemadfard@yahoo.com 